\title{
A detailed analysis of early events during in-vitro fertilization of bovine follicular oocytes
}

\author{
K. P. Xu and T. Greve \\ Department of Animal Reproduction, Royal Veterinary and Agricultural University, Bülowsvej 13, \\ DK-1870 Frederiksberg C, Denmark
}

\begin{abstract}
Summary. Bovine follicular oocytes collected at slaughter were matured and fertilized in vitro with in-vitro capacitated spermatozoa. Analysis of 621 penetrated ova fixed at various times after in-vitro insemination led to definition of 6 stages of early development. A time sequence for sperm penetration, sperm head decondensation, male pronucleus formation, the activation of second meiotic division, female chromosome decondensation and pronucleus development was established. First sperm penetration into the ooplasm was recorded $6 \mathrm{~h}$ after insemination; $1-2 \mathrm{~h}$ was required for the sperm head to decondense and another 4-6h to develop into the opposing pronucleus stage. Synkaryosis and first cleavage occurred $28 \mathrm{~h}$ after fertilization. Examination of the early stages revealed four types of abnormalities, i.e. polyspermy, polygyny, asynchrony between male and female pronucleus development, and preactivation of cytokinesis.
\end{abstract}

Keywords: in-vitro fertilization; cow; follicular oocytes; light microscopy; abnormalities

\section{Introduction}

Few studies have dealt with the morphological features of the early events of fertilization in vivo as well as in vitro in the large domestic species, mainly because of technical limitations. Two large pronuclei were found $15 \mathrm{~h}$ after mating in the rabbit (Zamboni \& Mastroianni, 1966), and Hunter (1972) presented evidence that opposing pronuclei appeared $5 \mathrm{~h}$ after mating in the pig. Accurate timing of events is difficult because the time required for pronuclear development is not only species-specific, but also affected by the assessment of the ovulation time and the time required for sperm capacitation in vivo (Hyttel et al., 1988).

The aims of this study were (1) to study the sequential changes associated with bovine fertilization in vitro, and (2) to reveal some of the abnormalities occurring during this process.

\section{Materials and Methods}

Bovine follicular oocytes collected at a local slaughterhouse were matured in vitro for up to $27 \mathrm{~h}$ as described previously (Xu, 1987; Xu et al., 1986b, 1987a). Subsequently, oocytes were treated with $0 \cdot 1 \%$ hyaluronidase for 1-2 min to remove part of the cumulus cells. Fresh as well as frozen semen samples from bulls of known fertility were used. Swim-up separation and heparin treatment were applied as basically described by Parrish et al. (1986) with some modifications. Approximately $1 \times 10^{6}$ spermatozoa/ml were used in a 50 - $\mu$ l drop containing 5 oocytes in each and covered by paraffin oil. Sperm-oocyte co-culture was carried out at $39^{\circ} \mathrm{C}$, in $5 \% \mathrm{CO}_{2} /$ air of high humidity.

Ova were fixed at 4, 6, 8, 12, 16, 20, 24 and $28 \mathrm{~h}$ after insemination in vitro. Fixation was accomplished in methanol: acetic acid $(3: 1, \mathrm{v} / \mathrm{v})$ for $48 \mathrm{~h}$ and the ova were stained with $1 \%$ aceto-orcein. The sequence of total sperm penetration into ooplasm, i.e. including the sperm tail, sperm head decondensation, completion of second meiotic division, and male and female pronuclear development were recorded and classified microscopically in 6 developmental stages. The classification criteria are described in Table 1, and some of the developmental stages are depicted in Figs $1-13$. 

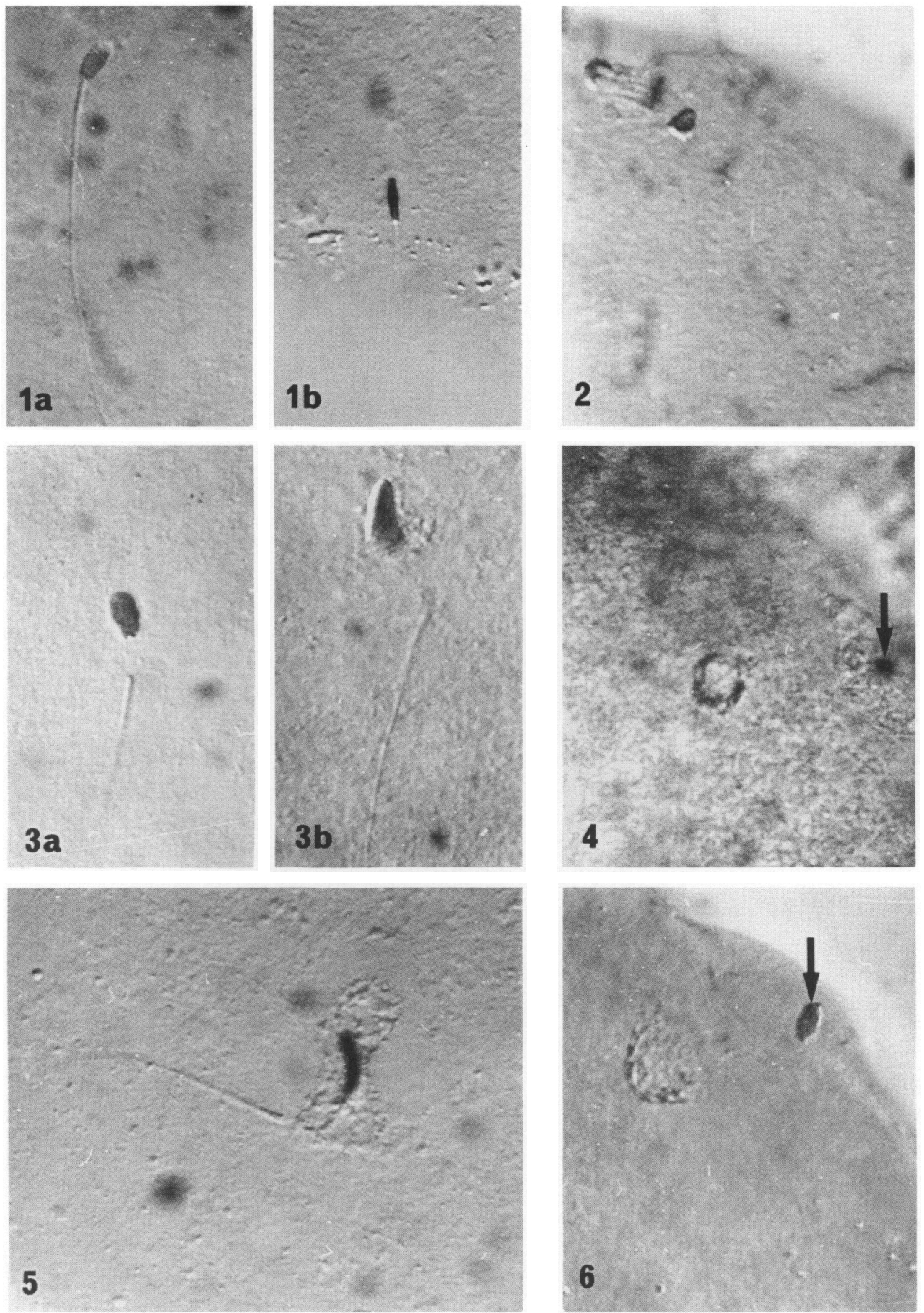
Table 1. Descriptions of the developmental stages of the male and female pronuclei (PN)

\section{Male}

Female

PN-I The complete spermatozoon is in the ooplasm, head stains heavily, no sign of decondensation is seen, tail is still attached to head (Figs la \& b)

PN-2 Sperm head starts to decondense (Fig. 3a), enlarges in size (Fig. 3b), stains less, and tail is detached

PN-3 Sperm head is further decondensed, nuclear envelope starts to form, midpiece is found in the vicinity of the head (Fig. 5)
Chromosomes are contracted to a dot, or second meiotic division has just started, (ana-telophaseII) (Fig. 2)

Second polar body is in the process of extrusion, or second meiotic division is completed (Fig. 4)

Chromosome decondensation occurs, nuclear envelope starts to form, second polar body is located close to the PN (Fig. 6)

PN-4 Chromosome decondensation is completed, the more or less spherical PNs are surrounded by a complete envelope (Fig. 7)

PN-5 PNs enlarge in size, the PN contents stain evenly, second polar body and the sperm tail can still be located (Fig. 7)

PN-6 PNs reach maximum size, the distance between the two is very small, often sperm tail is still visible (Fig. 8)

\section{Results}

\section{Sequential changes during early in-vitro fertilization}

At $4 \mathrm{~h}$ after insemination, no sperm portion was found in the ooplasm. Evidence of sperm penetration $(4 / 34,11 \cdot 8 \%$ ) was observed at $6 \mathrm{~h}$. At $8 \mathrm{~h}$, most pronuclei were at early stages (Table 2 ). At $12 \mathrm{~h}$, a range of different stages was found, and a few oocytes had already reached late pronucleus stages (Table 2). The penetration rate increased proportionally with the co-culture time until $16 \mathrm{~h}$, and reached a maximum level at $28 \mathrm{~h}(47 / 57,82 \cdot 5 \%)$. At 16-28 h (Table 2) ova were at the later pronuclear stages. First cleavage plate and the 2-celled ova were observed at $28 \mathrm{~h}$ (Fig. 9).

The developmental stages of the male and female pronuclei, within an individual ovum, are not necessarily identical. This synchrony/asynchrony is presented in Table 2.

\section{Abnormalities during early in-vitro fertilization}

Four main types of abnormalities were noticed: polyspermy (Fig. 10), polygyny (Fig. 11), asynchronous development of male and female pronuclei (Fig. 12), and preactivation of cytokinesis (Fig. 13).

Fig. 1. Male PN-1: the spermatozoon is in the ooplasm, the tail is still attached to the head, a horizontal view (a) and a side view (b) of the sperm head. $\times 620$.

Fig. 2. Female PN-1: the anaphase of the second meiotic division is seen and abstriction of the second polar body has started. $\times 620$.

Fig. 3. Male PN-2: the sperm heads start to decondense (a), and enlarge in size (b), the tail is detached from the head (a \& b). $\times 620$.

Fig. 4. Female PN-2: the chromosomes start to decondense and the second polar body (arrow) is in the vicinity of the female PN. $\times 620$.

Fig. 5. Male PN-3: the sperm head is further decondensed, nuclear envelope starts to form. $\times 620$.

Fig. 6. Female PN-3: the chromosomes are further decondensed, the second polar body is still close to the PN. $\times 620$. 

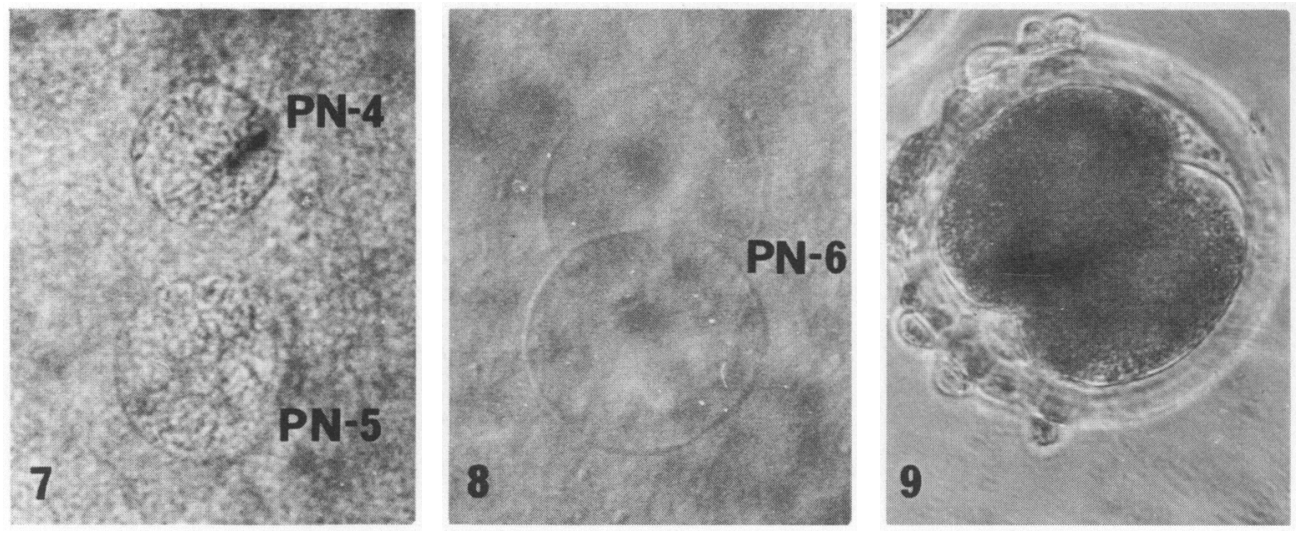

Fig. 7. PN-4: a male pronucleus (sperm tail is not visible), which shows almost completely decondensed chromosomes and a well formed PN envelope. PN-5: a female pronucleus (the second polar body is rather distant and is not visible), which has further enlarged in size. $\times 620$.

Fig. 8. PN-6: two well developed PNs are closely located and are spherical in shape. This is a stage close to synkaryosis (sperm tail and second polar body are not visible). $\times 620$.

Fig. 9. A 2-celled ovum observed at $31 \mathrm{~h}$ after insemination with two symmetric blastomeres and a few corona cells attached. $\times 270$.

Polyspermy was first observed at $12 \mathrm{~h}$ after insemination. When the penetration rate achieved its highest value at $16 \mathrm{~h}$, the percentage of polyspermy was $10 \cdot 7 \%$. As the co-culture time progressed the percentage increased further, but remained at a low level. Overall, the frequency of polyspermy at $6,8,12,16,20,24$ and $28 \mathrm{~h}$ after insemination were $0,0,6 \cdot 3,10 \cdot 7,5 \cdot 2,16 \cdot 1$ and $17 \cdot 0 \%$, respectively. In addition, $72 \cdot 4,19 \cdot 0,6 \cdot 9$ and $1.7 \%$ of polyspermic ova were penetrated by 2 , 3,4 or 5 spermatozoa, respectively.

Polygyny, defined as ova in which neither second polar body nor any trace of sperm tail in the ooplasm could be identified, accounted for a small proportion of the abnormalities. Often, these ova developed two or more pronuclei. The frequencies of this are shown in Table 3.

Penetrated ova, in which two pronuclei were recorded at identical stages or only exhibiting one stage of deviation, were regarded as representing synchronous development of male and female pronuclei, while those pronuclei beyond two stages of developmental difference were regarded as asynchronous. The proportions of asynchronous ova were $7 \cdot 1,35 \cdot 7,26 \cdot 9,40 \cdot 0,33 \cdot 9$ and $12 \cdot 8 \%$ at $8,12,16,20,24$ and $28 \mathrm{~h}$, respectively after insemination. Asynchrony between male and female pronuclear development of more than two deviating stages was the predominant abnormal feature in the present in-vitro fertilization system. Failure of the sperm head to decondense and retardation of pronucleus development were the main causes (Table 2). Delay in the female pronucleus was also recorded, but at a very small proportion.

Preactivation of cytokinesis, i.e. symmetrical cytoplasmic cleavage before synkaryosis, indicated by the location of early pronucleus stages (pronuclei 1 to 5 ) together with the presence of a sperm tail in one of the cellular compartments was first observed at $12 \mathrm{~h}$, and reached its highest level at 24 and $28 \mathrm{~h}$ after insemination, with $4 \cdot 8 \%$ and $6 \cdot 4 \%$, respectively. The overall incidence was $2 \cdot 3 \%$ $(14 / 621)$.

\section{Discussion}

The present study is the first to demonstrate that early fertilization events in cattle can be classified into 6 distinct stages by means of light microscopy. The general trend in the early developmental period seems clear as 621 penetrated ova were included for the analysis. 

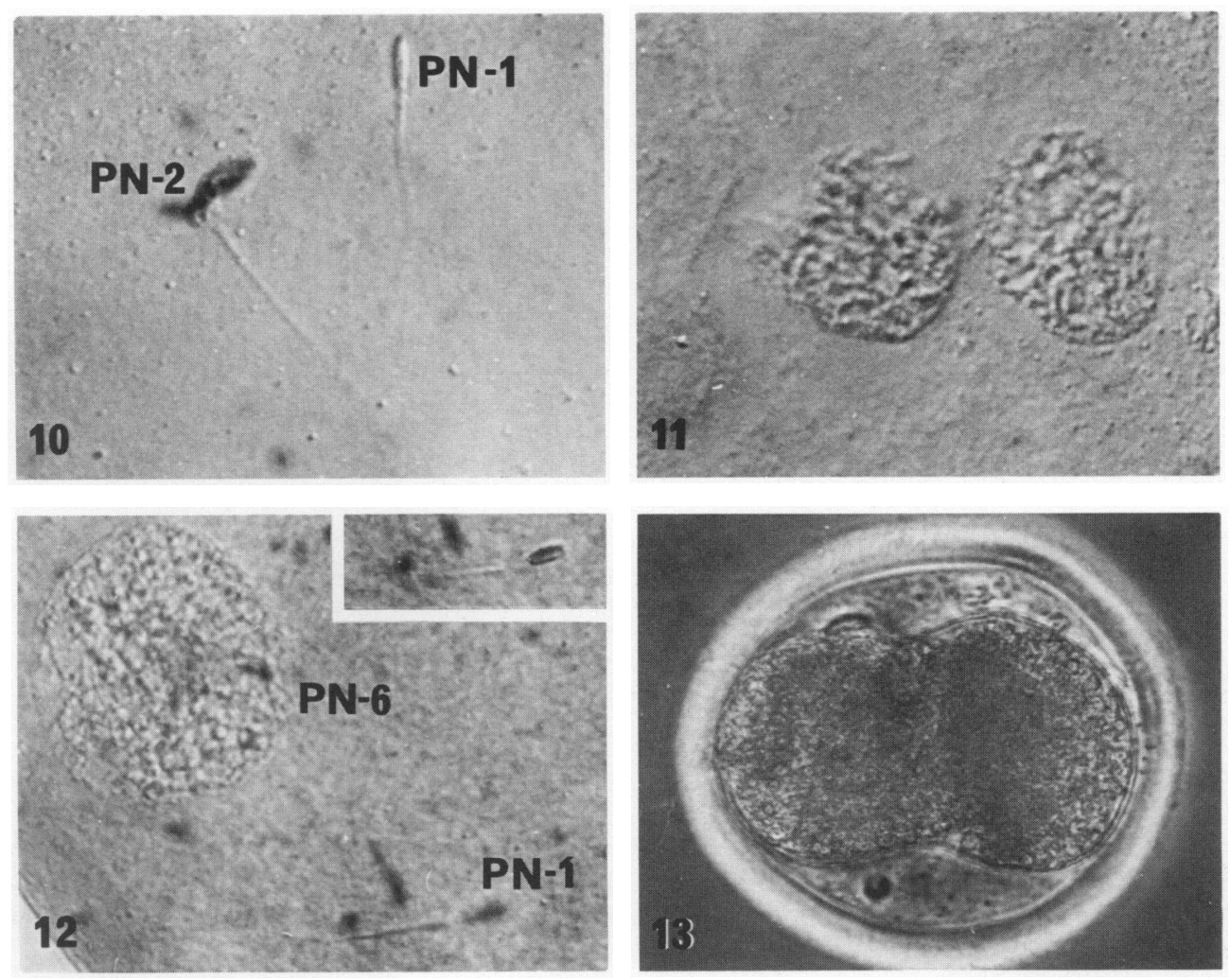

Fig. 10. A polyspermic ovum, in which there are two spermatozoa, one at the PN-1 and the other at the PN-2 stage. $\times 620$.

Fig. 11. A polygynous ovum, with two well developed PNs; neither sperm tail nor second polar body is visible. $\times 620$.

Fig. 12. An asynchronously developed ovum, with a female PN-6 and a male PN-1; inset focusses on the same spermatozoon. $\times 500$.

Fig. 13. A preactivated ovum in the process of division observed before fixation at $12 \mathrm{~h}$ after insemination. After fixation and staining, a male PN-3 and a female PN-4 were found in each cellular compartment. $\times 350$.

As we still do not know the exact time required for capacitated spermatozoa to penetrate the cumulus investments and the zona pellucida and finally fuse with the oolemma, this study can only conclude that the minimum time needed for these events was less than $6 \mathrm{~h}$. This is close to the estimated time for bull sperm capacitation in vivo (Hunter, 1980), but much longer than that found in the cat (Niwa et al., 1985). Sperm head decondensation (from pronucleus 1 to pronucleus 3 ) occurred within $1-2 \mathrm{~h}$ after penetration, and it seems that $4-6 \mathrm{~h}$ were required for the decondensed chromatin to develop into the subsequent pronuclear stages (from pronucleus 3 to pronucleus 6 ), which is similar to the $5 \mathrm{~h}$ found in pig (Hunter, 1972).

Penetration over $10 \mathrm{~h}$, beginning at $6 \mathrm{~h}$ after insemination, was probably a manifestation of the heterogeneity or staggering of the time required for individual spermatozoa to complete their capacitation and acrosome reaction (Bedford, 1983). Consequently, the developmental stages varied considerably among the ova, as has also been reported during in-vivo fertilization in superovulated cattle (Hyttel et al., 1988). 
Table 2. Distribution of the developmental stages of male and female pronuclei (PN) at various hours after insemination in vitro*

\begin{tabular}{|c|c|c|c|c|c|c|c|c|c|c|c|c|}
\hline \multirow[b]{2}{*}{ Male } & \multicolumn{6}{|c|}{$\begin{array}{c}\text { At } 8 h(N=13) \\
\text { Female }\end{array}$} & \multicolumn{6}{|c|}{$\begin{array}{c}\text { At } 12 h(N=126) \\
\text { Female }\end{array}$} \\
\hline & PN-1 & PN-2 & PN-3 & PN-4 & PN-5 & PN-6 & PN-1 & PN-2 & PN-3 & PN-4 & PN-5 & PN-6 \\
\hline PN-6 & & & & & & & & & & & 1 & 2 \\
\hline PN-5 & & & & & & & & & 1 & 3 & 14 & 1 \\
\hline PN-4 & & & & & & & & & & 9 & 11 & 2 \\
\hline PN-3 & & & & & & & & 1 & 10 & 1 & 8 & 6 \\
\hline PN-2 & & 2 & 2 & & 1 & & 13 & 7 & 10 & 6 & 10 & 5 \\
\hline \multirow[t]{2}{*}{ PN-1 } & & 8 & & & & & & & & 3 & 1 & 1 \\
\hline & \multicolumn{6}{|c|}{$\begin{array}{c}\text { At } 16 h(N=234) \\
\text { Female }\end{array}$} & \multicolumn{6}{|c|}{$\begin{array}{c}\text { At } 20 \mathrm{~h}(N=135) \\
\text { Female }\end{array}$} \\
\hline Male & PN-1 & PN-2 & PN-3 & PN-4 & PN-5 & PN-6 & PN-1 & $\mathrm{PN}-2$ & PN-3 & PN-4 & PN-5 & PN-6 \\
\hline PN-6 & & & 2 & 2 & 5 & 18 & & & & 1 & 3 & 21 \\
\hline PN-5 & & & 3 & 11 & 57 & 14 & & & & & 16 & 11 \\
\hline PN-4 & & & & 6 & 22 & 2 & & & & & 3 & 3 \\
\hline PN-3 & & & 3 & 3 & 7 & 4 & & & & 1 & 5 & 1 \\
\hline PN-2 & & 3 & 11 & 5 & 14 & 11 & & 2 & 3 & 9 & 11 & 6 \\
\hline \multirow[t]{2}{*}{ PN.1 } & 7 & 10 & 5 & 4 & 4 & 1 & 3 & 17 & 5 & 5 & 7 & 2 \\
\hline & \multicolumn{6}{|c|}{$\begin{array}{c}\text { At } 24 h(N=62) \\
\text { Female }\end{array}$} & \multicolumn{6}{|c|}{$\begin{array}{c}\text { At } 28 h(N=47) \\
\text { Female }\end{array}$} \\
\hline Male & PN-1 & $\mathrm{PN}-2$ & PN-3 & PN-4 & PN-5 & PN-6 & PN-1 & PN-2 & PN-3 & PN-4 & PN-5 & PN-6 \\
\hline PN-6 & & & & & & 26 & & & & & & 28 \\
\hline PN-5 & & & & & 3 & 4 & & & & & 4 & 7 \\
\hline PN-4 & & & & & 2 & 6 & & & & & 2 & 4 \\
\hline PN-3 & & & & & 2 & & & & & & & \\
\hline PN-2 & & 2 & & 1 & 3 & 2 & & & & & & \\
\hline PN-1 & 1 & 4 & & 1 & 3 & 2 & & & & & & 2 \\
\hline
\end{tabular}

*The bold numbers represent the number of ova in which the male and female pronuclei are synchronous.

The time for the first appearance of the 2-cell stage is comparable with reports on in-vivo fertilization (Hyttel et al., 1988), if $6 \mathrm{~h}$ for sperm capacitation are subtracted, and it is also in agreement with a recent finding by Barnes et al. (1987), but considerably shorter than the $44 \cdot 5 \mathrm{~h}$ reported by Sirard \& Lambert (1985).

Although normal in-vitro fertilization procedures are now well established in many mammalian species, careful examinations of ova at the early fertilized stage have revealed some abnormalities (Plachot et al., 1985, Schulman et al., 1985). The present polyspermy frequencies were comparable to those in other in-vitro fertilization studies in cattle (Parrish et al., 1986) and are low in comparison with findings for the pig (Cheng et al., 1986), suggesting that the block against polyspermy, at the level of zona and/or oolemma, was more efficient in cattle. Polygyny, probably resulting from failure of the first or second polar body to extrude, or from parthenogenetic activation (Xu et al., 1986a), was observed, but at a low incidence during the whole period studied.

By a comparative analysis of the progressive development of the male and female pronuclei, it is clearly shown that asynchrony was the predominant abnormal feature in this system. Sperm head decondensation may stop at any stage of development. Although the mechanisms by which sperm nuclear decondensation and pronucleus formation occur are largely unknown (for review see Zirkin 
Table 3. Number and frequencies of polygyny

\begin{tabular}{|c|c|c|c|c|c|c|c|c|}
\hline \multirow{2}{*}{$\begin{array}{l}\text { No. of } \\
\text { female } \\
\text { pronuclei }\end{array}$} & \multicolumn{7}{|c|}{ Hours after insemination } & \multirow[b]{2}{*}{$(\%) \ddagger$} \\
\hline & 6 & 8 & 12 & 16 & 20 & 24 & 28 & \\
\hline 2 & $\ldots$ & 1 & 1 & 4 & 5 & 3 & - & $\begin{array}{r}14 / 18 \\
(77 \cdot 8)\end{array}$ \\
\hline 3 & - & 1 & - & 1 & - & - & - & $\begin{array}{r}2 / 18 \\
(11 \cdot 1)\end{array}$ \\
\hline 4 & - & - & 1 & - & - & - & 1 & $\begin{array}{r}2 / 18 \\
(11 \cdot 1)\end{array}$ \\
\hline $\begin{array}{l}\mathrm{Pg} / \mathrm{Pe}^{*} \\
(\%) \dagger\end{array}$ & $\overline{(0)}$ & $\begin{array}{r}2 / 13 \\
(15.4)\end{array}$ & $\begin{array}{l}2 / 126 \\
(1 \cdot 6)\end{array}$ & $\begin{array}{c}5 / 234 \\
(2 \cdot 1)\end{array}$ & $\begin{array}{c}3 / 135 \\
(3 \cdot 7)\end{array}$ & $\begin{array}{c}3 / 62 \\
(4 \cdot 8)\end{array}$ & $\begin{array}{l}1 / 47 \\
(2 \cdot 1)\end{array}$ & \\
\hline
\end{tabular}

*No. of polygynous ova per no. of penetrated ova.

$†$ Polygynous frequencies at the various times after insemination.

¥Frequencies of different number of female pronuclei per polygynous ovum.

et al., 1985), our findings do not support the suggestion by Fulka et al. (1982) that a cytoplasmic substance responsible for male pronucleus formation is present in about $50 \%$ of randomly selected bovine oocytes. Indeed the suggestion that such a substance is present in various amounts (Hunter, 1967; Calvin et al., 1986) seems more likely. As soon as the spermatozoon penetrates the ooplasm, the female chromatin is activated. Subsequently, only a very small proportion of the female pronuclei developed at a slower rate than their male counterparts. It is our impression that in a substantial proportion of the ova, both male and female pronuclear development was retarded. The final drop in the frequency of asynchronous development of pronucleus at $28 \mathrm{~h}$ after insemination may be explained by further development of the retarded male pronucleus while the female pronucleus is still at the long-lasting pronucleus 6 stage.

Fragmentation during in-vitro fertilization has been noticed by previous investigators (for review see Bavister, 1981). In our opinion preactivation of cytokinesis, however, may be different from fragmentation. Preactivation of cytokinesis comprises symmetrical division of the ooplasm similar to normal cytokinesis. The pronuclear stages may be found in one or each of the two cellular compartments. This supports our previous notion that cytokinesis and karyokinesis might be two independent processes $(\mathrm{Xu}, 1987)$. Since the polyspermy frequency among the preactivated ova is much higher than that of the total, it is very likely that polyspermy is implicated in this preactivation.

In conclusion, the present study shows that early events of bovine fertilization in vitro are similar to the in-vivo conditions (Hyttel et al., 1988). Improved methods for sperm capacitation and oocyte maturation may eventually reduce the incidence of abnormal fertilization and produce normal zygotes that can develop into pregnancies (Xu et al., 1987b).

We thank Dr P. Hyttel for valuable discussion and critical reading of the manuscript; and Mrs Inger Heinze and Ms Inger Madsen for technical assistance and for preparing the photographs. This work was supported by grants from the Danish Agricultural and Veterinary Research Council and the Leo Research Foundation.

\section{References}

Barnes, F.L., Parrish, J.J., Susko-Parrish, J.L. \& First, N.L. (1987) Morphological and molecular aspects of early development in the bovine. Theriogenology 27 , 210. Abstr.

Bavister, B.D. (1981) Analysis of culture media for in vitro fertilization and criteria for success. In Fertilization and Embryonic Development In Vitro, pp. 41-60. Eds L. Mastroianni, Jr \& J. D. Biggers. Plenum Press, New York.

Bedford, J.M. (1983) Significance of the need for sperm 
capacitation before fertilization in eutherian mammals. Biol. Reprod. 33, 698-704.

Calvin, H.I., Grosshans, K. \& Blake, E.J. (1986) Estimation and manipulation of glutathione levels in prepuberal mouse ovaries and ova: relevance to sperm nucleus transformation in the fertilized egg. Gamete Res. 14, 265-275.

Cheng, W.T.K., Moor, R.M. \& Polge, C. (1986) In-vitro fertilization of pig and sheep oocytes matured in vivo and in vitro. Theriogenology 25, 146, Abstr.

Fulka, J., Jr, Pavlok, J.A. \& Fulka, J. (1982) In-vitro fertilization of zona-free bovine oocytes matured in culture. J. Reprod. Fert. 64, 495-499.

Hunter, R.H.F. (1967) Polyspermic fertilization in pigs during the luteal phase of the estrus cycle. $J$. exp. Zool. 165, 451-466.

Hunter, R.H.F. (1972) Fertilization in the pig: sequence of nuclear and cytoplasmic events. J. Reprod. Fert. 29, 395406 .

Hunter, R.H.F. (1980) Physiology and Technology of Reproduction in Female Domestic Animals. Academic Press, London.

Hyttel, P., Greve, T. \& Callesen, H. (1988) Ultrastructure of in-vivo fertilization in superovulated cattle. $J$. Reprod. Fert. 82, 1-13.

Niwa, K., Ohara, K., Hosoi, Y. \& Iritani, A. (1985) Early events of in-vitro fertilization of cat eggs by epididymal spermatozoa. J. Reprod. Fert. 74, 657-660.

Parrish, J.J., Susko-Parrish, J.L., Leibfried-Rutledge, M.L., Critser, E.S., Eyestone, W.H. \& First, N.L. (1986) Bovine in-vitro fertilization with frozen thawed semen. Theriogenology 25, 591-600.

Plachot, M., Mandelbaum, J., Junca, A.-M., Baroux, J.-S. \& Cohen, J. (1985) Impairment of human embryo development after abnormal in-vitro fertilization. In In-Vitro Fertilization and Embryo Transfer, pp. 336341. Eds M. Seppälä \& R. G. Edwards. New York Academy of Sciences, New York.
Schulman, J.D., Dorfmann, A. \& Evans, M.I. (1985) Genetic aspects of in vitro fertilization. In In-Vitro Fertilization and Embryo Transfer, pp. 466-475. Eds M. Seppälä \& R. G. Edwards. New York Academy of Sciences, New York.

Sirard, M.A. \& Lambert, R.D. (1985) In-vitro fertilization of bovine follicular oocytes obtained by laparoscopy. Biol. Reprod. 33, 487-494.

Xu, K.P. (1987) Studies on the bovine follicular oocytes maturation and fertilization in vitro. Ph.D. thesis, Royal Veterinary and Agricultural University, Copenhagen.

Xu, K.P., Greve, T., Smith, S., Liehman, P., Callesen, H. \& Hyttel, P. (1986a) Parthenogenetic activation of cattle oocytes matured in vitro and cultured in rabbit oviducts. Theriogenology 25, 218, Abstr.

Xu, K.P., Greve, T., Smith, S. \& Hyttel, P. (1986b) Chronological changes of bovine follicular oocyte maturation in vitro. Acta vet. scand. 27, 505-519.

Xu; K.P., Høier, R. \& Greve, T. (1987a) Dynamic changes of estradiol concentration in two culture systems for bovine oocyte maturation in vitro. Theriogenology 27, 297, Abstr.

Xu, K.P., Greve, T., Callesen, H. \& Hyttel, P. (1987b) Pregnancy resulting from cattle oocytes matured and fertilized in vitro. J. Reprod. Fert. 81, 501-504.

Zamboni, L. \& Mastroianni, L., Jr (1966) Electron microscopic studies on rabbit ova. II. The penetrated tubal ovum. J. Ultrastruct. Res. 14, 118-132.

Zirkin, B.R., Soucek, D.A., Chang, T.S.K. \& Perreault, S.D. (1985) In-vitro and in-vivo studies of mammalian sperm nuclear decondensation. Gamete Res. 11, 349-365. 